\title{
Inkjet-Printed Organic Field-Effect Transistor by Using Composite Semiconductor Material of Carbon Nanoparticles and Poly(3-Hexylthiophene)
}

\author{
Chih-Ting Lin, ${ }^{1,2}$ Chun-Hao Hsu, ${ }^{1}$ Chang-Hung Lee, ${ }^{1}$ and Wen-Jung Wu ${ }^{3}$ \\ ${ }^{1}$ Graduate Institute of Electronics Engineering, National Taiwan University, Taipei 10617, Taiwan \\ ${ }^{2}$ Department of Electrical Engineering, National Taiwan University, Taipei 10617, Taiwan \\ ${ }^{3}$ Department of Engineering Science and Ocean Engineering, National Taiwan University, Taipei 10617, Taiwan
}

Correspondence should be addressed to Chih-Ting Lin, timlin@cc.ee.ntu.edu.tw and Wen-Jung Wu, wjwu@ntu.edu.tw

Received 26 February 2011; Revised 28 April 2011; Accepted 20 May 2011

Academic Editor: Werner Blau

Copyright () 2011 Chih-Ting Lin et al. This is an open access article distributed under the Creative Commons Attribution License, which permits unrestricted use, distribution, and reproduction in any medium, provided the original work is properly cited.

\begin{abstract}
Poly(3-hexylthiophene), P3HT, has been widely used in organic electronics as a semiconductor material. It suffers from the low carrier mobility characteristics. This limits P3HT to be employed in applications. Therefore, the blending semiconductor material, carbon nanoparticle (CNP), and P3HT, are developed and examined by inkjet-printing organic field-effect transistor technology in this work. The effective carrier mobility of fabricated OFETs can be enhanced by 8 folds with adding CNP and using $\mathrm{O}_{2}$ plasma treatment. At the same time, the transconductance of fabricated OFETs is also raised by 5 folds. Based on the observations of SEM, $\mathrm{XRD}$, and FTIR, these improvements are contributed to the local field induced by the formation of CNP/P3HT complexes. This observation presents an insight of the development in organic semiconductor materials. Moreover, this work also offers a low-cost and effective semiconductor material for inkjet-printing technology in the development of organic electronics.
\end{abstract}

\section{Introduction}

Organic electronics have received tremendous interests due to their potential applications in flexible electronics. Moreover, characteristics of organic electronics including low-cost and low-temperature process also promote the value of this research field. Therefore, various organic electronic devices have been proposed and implemented, such as organic thin film transistors (OTFTs) [1], largearea displays [2], solar cells [3-5], organic light-emitting diodes (OLEDs) $[6,7]$, radio frequency identification tags (RFIDs) [8], and sensors [9]. Among various fabrication methods to implement these organic electronics, printing technology is emphasized because of its compatibility to large-area fabrications and industrial mass productions. The printing techniques can be achieved by spin coating, roll-to-roll printing, screen printing, gravure printing, and inkjet printing. In these established printing techniques, inkjet-printing is one of the most intriguing techniques. Without any prepatterned process, it can directly deposit ink materials following a designed pattern on substrates in an in-situ manner [10]. Compared with other solutionbased printing processes, inkjet printing can reduce the ink material consumption by drop-on-demand design. It also overcomes the traditional contact and pattern-transferring problems. In addition, the high-resolution inkjet-printing techniques have been demonstrated up to $1 \mu \mathrm{m}$ or less [11, 12]. As a consequence, organic materials with nanowires, nanoparticles, and nanocrystal-polymer composites have been successfully used to implement organic electronics devices by inkjet-printing process [13-16].

On the other hand, the major obstacle of organic electronics, such as OFET, to be overcome is electrical characteristics. For example, the characteristics to be improved are transistor on-off ratio, threshold voltage, and transistor transconductance. To address these, previous research works have been proposed and demonstrated. For instance, selforganized layer [17] or self-assembly monolayer (SAM) [1820] have been employed to enhance mobility; the surface modification of electrodes [13] has been used to reduce 


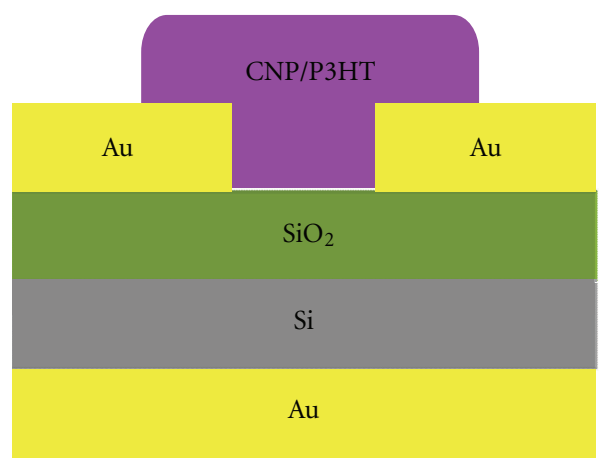

(a)

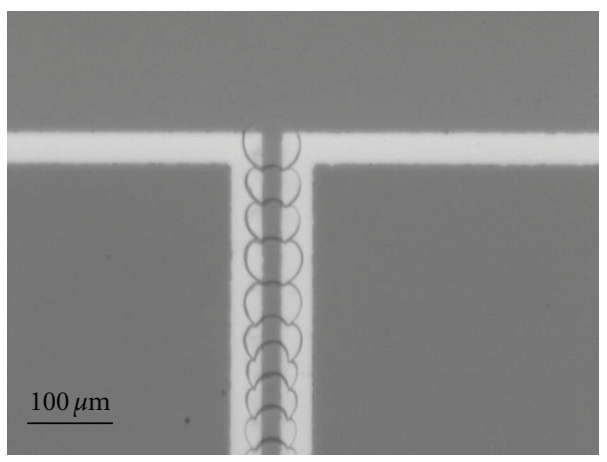

(c)

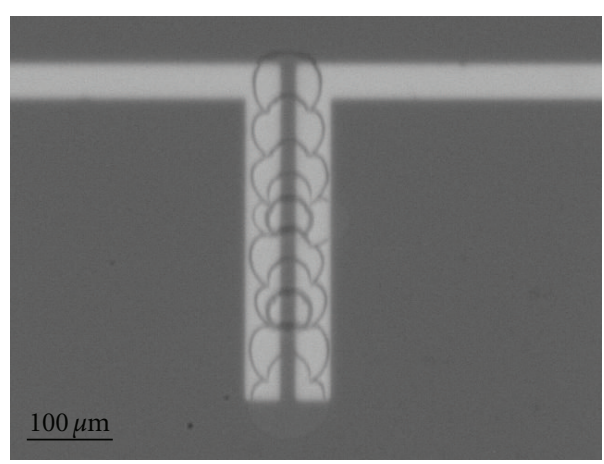

(b)

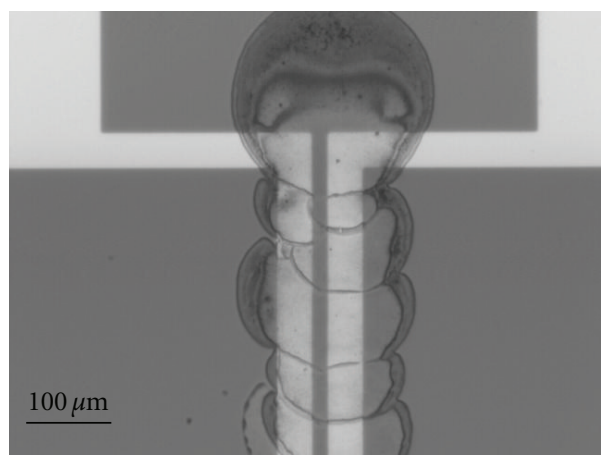

(d)

FIGURE 1: (a) Schematic representation of cross section of the inkjet-printed OFETs, (b), (c), and (d) microscope images of the OFETs for pristine $\mathrm{P} 3 \mathrm{HT}, \mathrm{CNP} / \mathrm{P} 3 \mathrm{HT}=0.1 \mathrm{wt} . \%$, and $\mathrm{CNP} / \mathrm{P} 3 \mathrm{HT}=10 \mathrm{wt} . \%$, respectively.

contact resistance; and blending organic materials [10] has been utilized to increase stability. Among various methods to improve the electrical characteristics of OFET, the composite of organic semiconductor and carbon nanostructure is attractive because of high compatibilities between these materials. For instance, carbon nanotubes were added into organic semiconductors to form composites serving as conducting bridge between organic semiconductors [21-24]. This can be used to improve the field-effect mobility. Because of CNT precipitation, however, the previously proposed methods of carbon nanotubes cannot be implemented with inkjet-printing technologies. As a result, it is necessary to develop a method compatible with inkjet printing to harness printing advantages.

In this work, poly(3-hexylthiophene) (P3HT) incorporated with carbon nanoparticles (CNPs) is used as the organic semiconductor material. The suspension capability of CNPs gives the feasibility to be implemented with inkjetprinting technologies. Utilizing this developed inkjet-printed $\mathrm{CNP} / \mathrm{P} 3 \mathrm{HT}$ blending semiconductor material, the mobility and transistor transconductance can be experimentally improved for 10 folds.

\section{Experiments}

The p-type silicon wafer with $200 \mathrm{~nm}$ thermal oxide is used as the substrate in this work. To form the source/drain electrodes, $20 \mathrm{~nm} \mathrm{Cr}$ and $200 \mathrm{~nm}$ Au are deposited on the top of the thermal oxide by evaporation. In addition, the oxide on the back side of the wafer is etched by BHF to expose the p-type silicon substrate. And gate contact is formed by deposition of $20 \mathrm{~nm} \mathrm{Cr}$ and $200 \mathrm{~nm} \mathrm{Au}$ after BHF etching. On the other hand, the CNP/P3HT semiconductor blending material is made at various concentrations $(0,0.1,1$, and 10 wt.\% with respect to P3HT). In specific, CNPs (Qf-Nano Tech. Co. Ltd., Taiwan, model: GF-PHG-1P) with different weights are added to the P3HT (Sigma Aldrich) solution to form the blending material in different concentration. At the same time, the P3HT solution is $0.3 \mathrm{wt} . \% \mathrm{P} 3 \mathrm{HT}$ dissolved in p-xylene. It should be noted that the CNP/P3HT blending solutions are prepared in nitrogen glove box $\left(\mathrm{H}_{2} \mathrm{O}<1 \mathrm{ppm}\right.$ and $\left.\mathrm{O}_{2}<1 \mathrm{ppm}\right)$ and stirred on the hotplate at $90^{\circ} \mathrm{C}$ for 1 hour.

Before depositing the CNP/P3HT semiconductor-composite material with different concentration, the substrate with fabricated electrodes are treated by $\mathrm{O}_{2}$ plasma (Harrick plasma, PDC-001, 10.2W) for $2 \mathrm{~min}$. Then CNP/P3HT can be inkjet printed on the top of electrodes to form the OFET structure under atmosphere conditions with relative humidity (RH) maintained at $20 \%$. After printing process, the printed $\mathrm{CNP} / \mathrm{P} 3 \mathrm{HT}$ semiconductor layer is cured at $70^{\circ} \mathrm{C}$ for 1 hour and annealed at $150^{\circ} \mathrm{C}$ for $10 \mathrm{~min}$ in nitrogen oven. In the last step to finish the device fabrication, the epoxy (Hisin Han Co. Ltd) is coated on the devices to serve as a protective layer. This protective layer is cured at $130^{\circ} \mathrm{C}$ for $30 \mathrm{~min}$ in a vacuum oven. The schematic and picture 


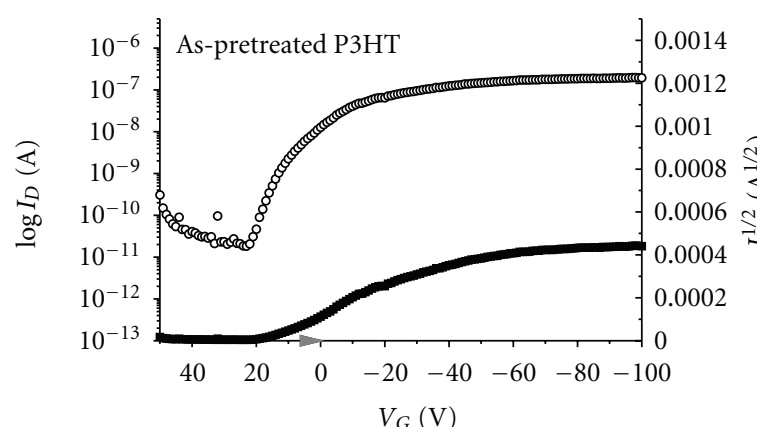

(a)

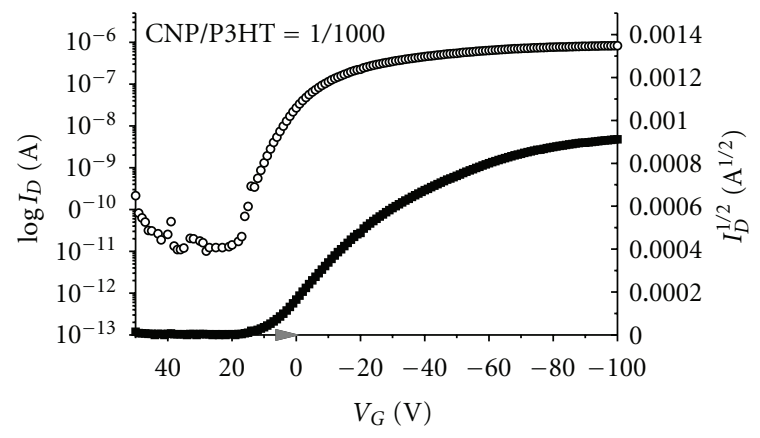

(c)

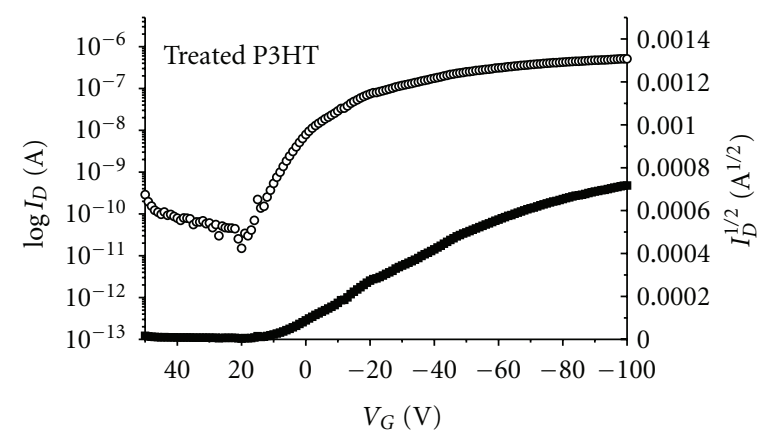

(b)

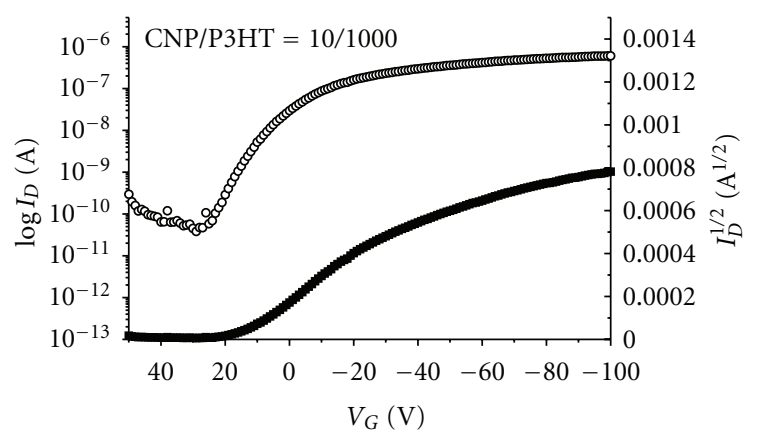

(d)

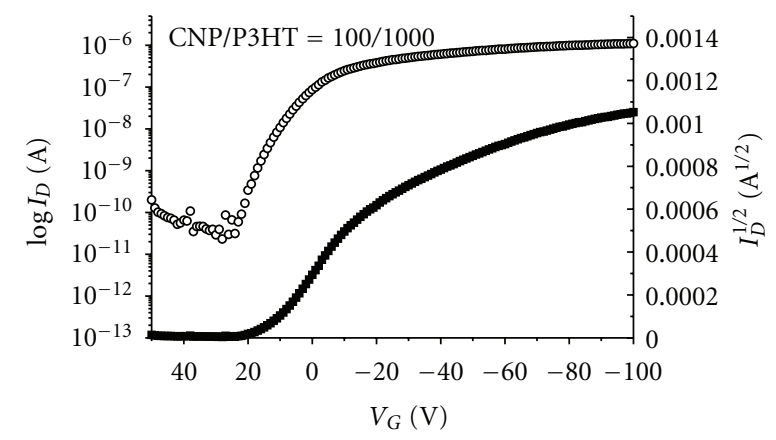

(e)

FIgURE 2: The $\mathrm{I}_{D}-\mathrm{V}_{\mathrm{GS}}$ of fabricated OFETs. (a) Pristine P3HT without $\mathrm{O}_{2}$ plasma treatment; (b) pristine P3HT with $\mathrm{O}_{2}$ plasma treatment; (c) $\mathrm{CNP} / \mathrm{P} 3 \mathrm{HT}=0.1 \mathrm{wt} . \%$ with $\mathrm{O}_{2}$ plasma treatment; (d) $\mathrm{CNP} / \mathrm{P} 3 \mathrm{HT}=1$ wt. $\%$ with $\mathrm{O}_{2}$ plasma treatment; $(\mathrm{e}) \mathrm{CNP} / \mathrm{P} 3 \mathrm{HT}=10$ wt. $\%$ with $\mathrm{O}_{2}$ plasma treatment.

of fabricated inkjet-printing device are shown in Figure 1. In specific, the channel length and channel width of the fabricated OFETs are $40 \mu \mathrm{m}$ and $800 \mu \mathrm{m}$, respectively.

To evaluate the performance of the fabricated OFETs, the electrical characteristics of the OFETs are measured by using Agilent $4156 \mathrm{C}$ semiconductor parameter analyzer under dark-atmosphere conditions with $\mathrm{RH}<25 \%$. Moreover, XRD (PANalytical, X' Pert PRO) and FTIR (Thermo Nicolet, Nexus470) are also performed to analyze CNP/P3HT composite material property.

\section{Results and Discussions}

To clearly demonstrate the transistor performance in different $\mathrm{CNP} / \mathrm{P} 3 \mathrm{HT}$ concentration, the $\mathrm{I}_{D}-\mathrm{V}_{\mathrm{GS}}$ characteristic of each OFET can be shown as Figure 2. Based on Figures 2(a) and 2(b), the drain current of $\mathrm{O}_{2}$ plasma-treated pristineP3HT OFET is larger than that without plasma treatment by 2 folds. From Figures 2(c), 2(d), and 2(e), in addition, this experimental result shows that the on-off ratio of different OFET keeps above $10^{4}$ even with different concentration of CNPs. To determine the on-off ratio, the maximum drain current in $\mathrm{I}_{D}-\mathrm{V}_{\mathrm{GS}}$ is defined as the on current. On the contrary, the minimum drain current in $\mathrm{I}_{D}-\mathrm{V}_{\mathrm{GS}}$ is defined as the off current. Moreover, Figure 3 illustrates $I_{D}-V_{D S}$ of each OFET to have the direct comparison. As the result obtained from Figure 2 shows, for the following CNP/P3HT OFET experiments, the devices are treated by $\mathrm{O}_{2}$ plasma before the printing of CNP/P3HT blending semiconductors. For CNP/P3HT = 0 wt.\%, 0.1 wt. $\%, 1$ wt. $\%$, and 10 wt.\%, shown in Figure 3, the on-off ratio are $3.4 \times 10^{4}, 8.2 \times$ $10^{4}, 1.6 \times 10^{4}$, and $4.8 \times 10^{4}$, respectively. In addition, the 


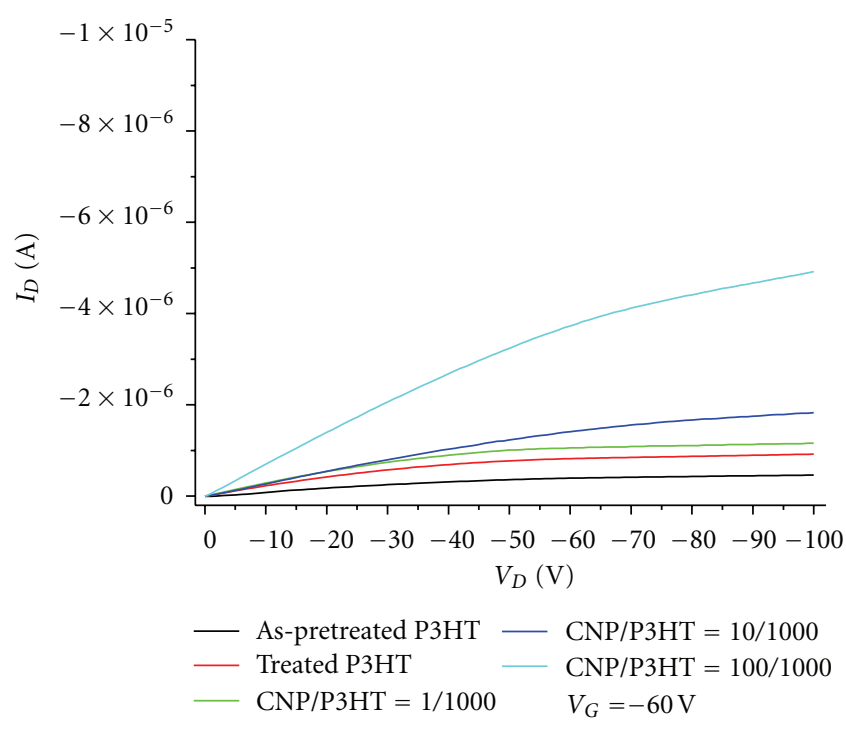

FIGURE 3: Output characteristics $\mathrm{I}_{D}-\mathrm{V}_{\mathrm{DS}}$ at $\mathrm{V}_{\mathrm{GS}}=-60 \mathrm{~V}$ for various $\mathrm{CNP} / \mathrm{P} 3 \mathrm{HT}$ concentrations.

threshold voltage, Vth, can also be extracted from $\mathrm{I}_{D}^{1 / 2}-\mathrm{V}_{\mathrm{GS}}$ as the device is biased in the linear region. It is identified as the extrapolation of the fitting line intercepts with zero drain current. Following this method, the threshold voltages are 8, $9.5,13$, and $15 \mathrm{~V}$, respectively. Finally, the average field-effect mobility was determined in the saturation region $\left(\mathrm{V}_{\mathrm{DS}}=\right.$ $-100 \mathrm{~V})$. Utilizing the Vth extracted above and the saturation current equation, the average mobility can be calculated. The calculated mobility of each OFET is $0.0014,0.0016,0.0017$, and $0.0060 \mathrm{~cm}^{2} / \mathrm{Vs}$, respectively. These results can be further summarized in Table 1.

From Table 1, we can find the fact that the threshold voltage of pristine P3HT OFET is shifted to negative $\mathrm{V}_{\mathrm{GS}}$ direction after $\mathrm{O}_{2}$ plasma treatment. In addition, the increase of drain current after $\mathrm{O}_{2}$ plasma treatment can be also found in both Figures 2 and 3. This threshold voltage shifting and current increase might be resulted from the elimination of space charges existing on the gold electrode surface by $\mathrm{O}_{2}$ plasma [25]. This charge elimination is because of the bombardment to form a thin film of $\mathrm{AuO}_{x}$ (Au-O band formation). This oxygen chemisorptions at the surface of $\mathrm{Au}$ increase the work function because of the electron transfer from gold to chemisorbed oxygen. As a consequence, the space charge can be reduced [26]. These space charges limit the current flowing through the interface. Therefore, $\mathrm{O}_{2}$ plasma can reduce the contact resistance by removing the space charges. At the same time, $\mathrm{O}_{2}$ plasma can also clean the electrode surface by removing carbohydrates, the barrier of current flows. Moreover, the surface potential of electrodes is also modified by $\mathrm{O}_{2}$ plasma. This promotes the adhesion of P3HT molecules and enhances the crystalline structure of $\mathrm{CNP} / \mathrm{P} 3 \mathrm{HT}$ thin film [27]. Both of these effects can improve the carrier diffusion length, decrease the resistance at gold/P3HT interface, and increase the drain current of OFETs. On the other hand, $\mathrm{O}_{2}$ plasma also charges the surface of the oxide. This induces oxygen vacancy defect and residual positive charge in the oxide [28]. This positive charge forms an opposite potential respect to the gate potential. As a consequence, the threshold voltage of OFETs is shifted to negative $\mathrm{V}_{\mathrm{GS}}$ direction after $\mathrm{O}_{2}$ plasma treatment.

For the effect of adding CNP in P3HT, from Table 1, the threshold voltage is shifted from $8 \mathrm{~V}$ to $15 \mathrm{~V}$ and the mobility is enhanced 5 folds, that is, from 0.0014 to $0.0060 \mathrm{~cm}^{2} / \mathrm{Vs}$, as increasing CNP concentration. This shift in threshold voltage is contributed to the formation of CNP/P3HT complexes. Since CNPs have much better conductance than P3HT, there is a local-induced field near CNPs as an external electrical field is applied. This localized electrical field can be enhanced because of the CNP's curvature [22]. As a result, the effective electrical field around CNP is larger than the electrical field generated by gate voltages. Therefore, the threshold voltage is moved toward positive $\mathrm{V}_{\mathrm{GS}}$. In addition, it can be observed that the off current will not be increased significantly before the CNP amount is increased to a critical concentration. This critical concentration leads to the percolation of CNP. And the CNP percolation generates the additional conduction path and enhances the off current of fabricated devices. As a consequence, the carrier transportation can be enhanced without degrading on-off ratio before CNP concentration is larger than the critical percolation concentration.

To further understand the detail of the developed CNP/ P3HT blending semiconductor material, scanning electron microscopy (SEM), X-ray diffraction (XRD), Fourier transform infrared spectroscopy (FTIR) measurement are carried out. The SEM picture of different concentration of $\mathrm{CNP} / \mathrm{P} 3 \mathrm{HT}$ is shown in Figure 4. Through Figure 4, the granule diameter of $\mathrm{CNP} / \mathrm{P} 3 \mathrm{HT}$ is around hundreds of $\mathrm{nm}$. Compared with the average diameter of CNP, that is, $35 \mathrm{~nm}$, it is clear that the CNP aggregation occurred even when CNP/P3HT blending solution is ultrasonicated before printing. These SEM pictures also indicate the formation of $\mathrm{CNP} / \mathrm{P} 3 \mathrm{HT}$ complexes. It should be noted that the aggregation becomes severed at the concentration of $10 \mathrm{wt} . \%$. This leads to the alternative conduction path formed by the CNP aggregation.

At the same time, X-ray diffraction (XRD) measurement is used to study the crystalline behavior of different concentration of CNP/P3HT blending material. This result can be shown in Figure 5. In the case of the pristine P3HT thin film, the intensity of the (100) reflection is resulted from the lamellar layer structure. The relative weak peak around the (101) is resulted from $\pi-\pi$ interchain stacking. It is clear that the pristine P3HT has a well-organized crystalline structure. As the ratio of CNP/P3HT increases from $0.1 \mathrm{wt} . \%$ to $10 \mathrm{wt} . \%$, the (100) XRD peak decreases. This result reveals that CNPs affect P3HT molecular alignment and destroy the crystalline structure of P3HT. This result can be clearly visualized in Figure 4 that the CNP aggregation is disordered.

To understand the material property through the bonding structure, FTIR is used to study the CNP/P3HT complex and shown as Figure 6. It shows the strong absorption bands at 2956, 2925, and $2855 \mathrm{~cm}^{-1}$, which means aliphatic C-H stretching of P3HT. As the concentration of $\mathrm{CNP} / \mathrm{P} 3 \mathrm{HT}$ increases, the absorption peak remains and no new absorption peak occurs. In other words, there 


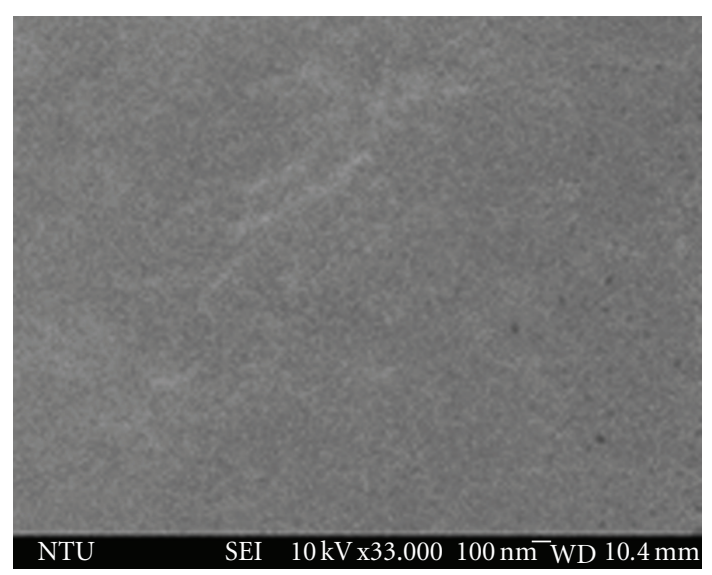

(a)

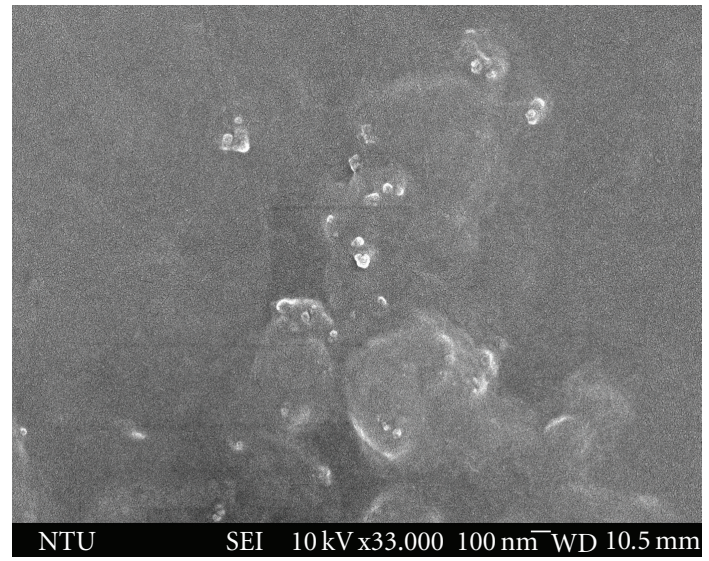

(c)

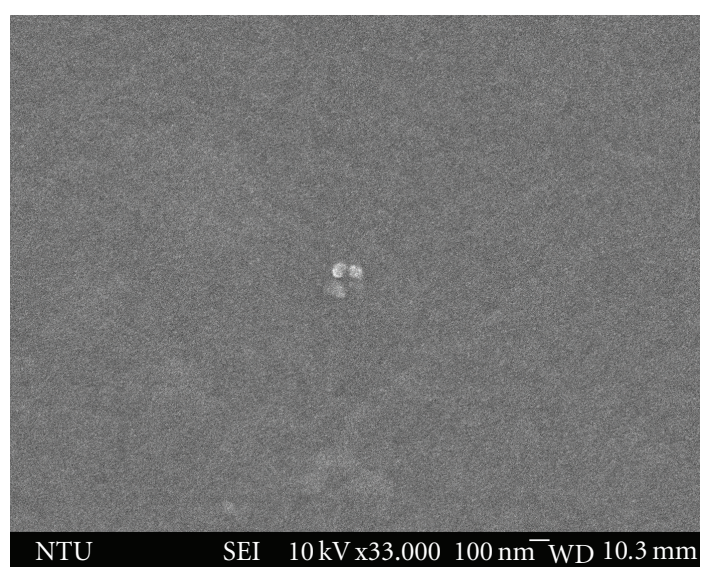

(b)

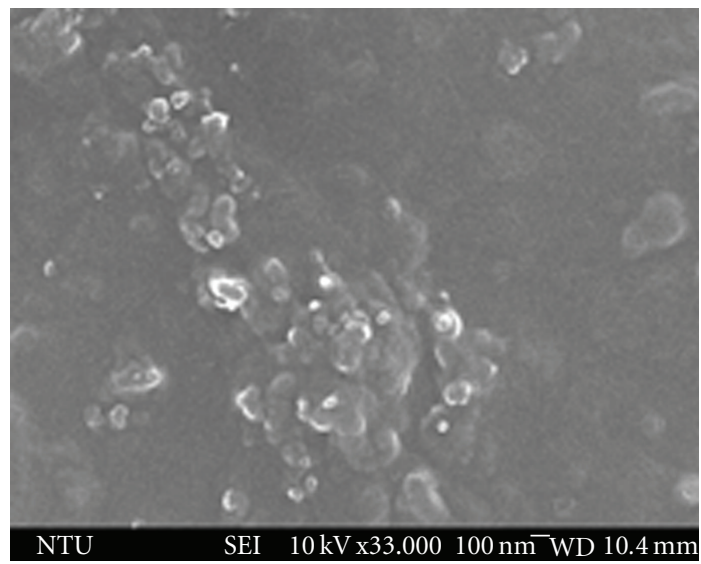

(d)

FIGURE 4: The SEM image for various concentration of CNP/P3HT blending solution (a) pristine P3HT; (b) CNP/P3HT = 0.1 wt.\%; (c) $\mathrm{CNP} / \mathrm{P} 3 \mathrm{HT}=1 \mathrm{wt} . \%$; (d) CNPP3HT $=10$ wt. $\%$.

TABLE 1: The experiment result of different OFETs.

\begin{tabular}{lccccc}
\hline & Pristine P3HT (as-pretreated) & Pristine P3HT & CNP/P3HT $=1 / 1000$ & CNP/P3HT $=10 / 1000$ & CNP/P3HT $=100 / 1000$ \\
\hline On/Off ratio & $1.07 \mathrm{E} 4$ & $3.41 \mathrm{E} 4$ & $8.24 \mathrm{E} 4$ & $1.60 \mathrm{E} 4$ & $4.76 \mathrm{E} 4$ \\
Vth $(\mathrm{V})$ & 12 & 8 & 9.5 & 13 & 15 \\
Mobility $\left(\mathrm{cm}^{2} / \mathrm{Vs}\right)$ & 0.0007 & 0.0014 & 0.0016 & 0.0017 & 0.0060 \\
\hline
\end{tabular}

is no additional bonding formation through the addition of CNPs. As a result, there is no bonding formation within the $\mathrm{CNP} / \mathrm{P} 3 \mathrm{HT}$ complex. In the previous research work [24], the chemically functionalized multiwall carbon nanotubes (MWCNTs) formed the P3HT-grafted-MWCNTs (g-MWCNTs) to enhance the carrier mobility by establishing chemical bonds for charge transferring. Compared with this previous research work, CNP/P3HT complexes developed at this work promote the carrier mobility without bonding formation between CNP and P3HT. This leads to the major advantage of reducing the cost and complexity to prepare the material.

In general, the disorderliness in crystalline structure leads to a decrease in carrier mobility. In addition, there is no chemical-bonding formation within CNP/P3HT complex. In other words, the direct carrier transportation between CNPs and P3HT cannot be promoted within CNP/P3HT complex. Since there is less alternative conduction path in low concentration of CNP/P3HT, that is, $0.1 \mathrm{wt} . \%$ and $1 \mathrm{wt} . \%$, adding CNP should decrease the drain current and effective mobility. However, our experimental result indicates an enhancement in carrier mobility with an increase in CNP concentration. This result can be contributed to the localized field enhancement induced by CNP/P3HT complex [22]. Moreover, the hole-injection barrier of P3HT can be reduced by adding carbon nanostructures [29]. As a consequence, the overall performance of developed OFETs is enhanced by using CNP/P3HT as semiconductor layers. This 
TABLE 2: The experimental transconductance of developed OFETs.

\begin{tabular}{lccccc}
\hline & $\begin{array}{c}\text { Pristine P3HT } \\
\text { (as pretreated) }\end{array}$ & Pristine P3HT & $\mathrm{CNP} / \mathrm{P} 3 \mathrm{HT}=1 / 1000$ & $\mathrm{CNP} / \mathrm{P} 3 \mathrm{HT}=10 / 1000$ & $\mathrm{CNP} / \mathrm{P} 3 \mathrm{HT}=100 / 1000$ \\
\hline Transconductance (nS) & 2.8 & 4.5 & 11 & 7.2 & 16 \\
\hline
\end{tabular}

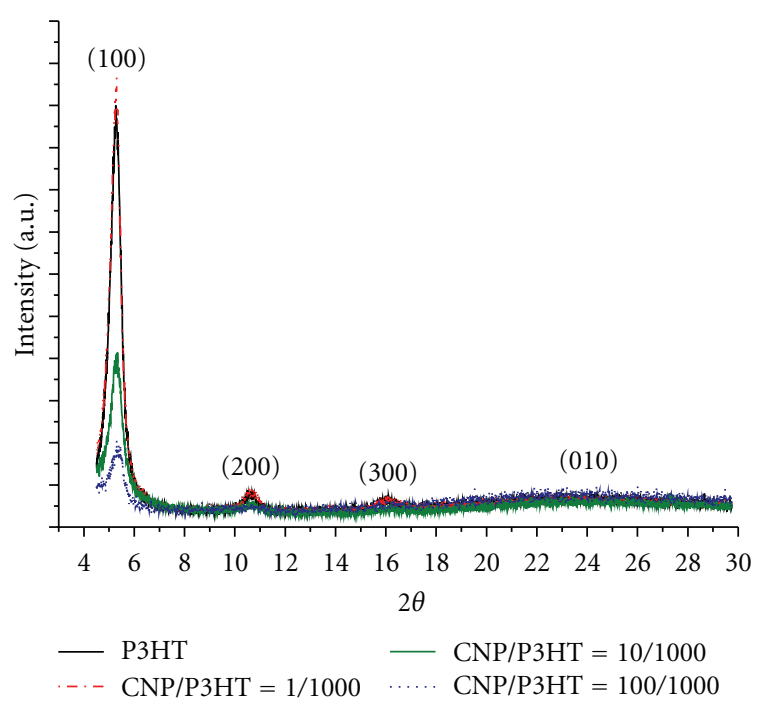

FIGURE 5: XRD image of pristine CNP/P3HT and different CNP concentrations.

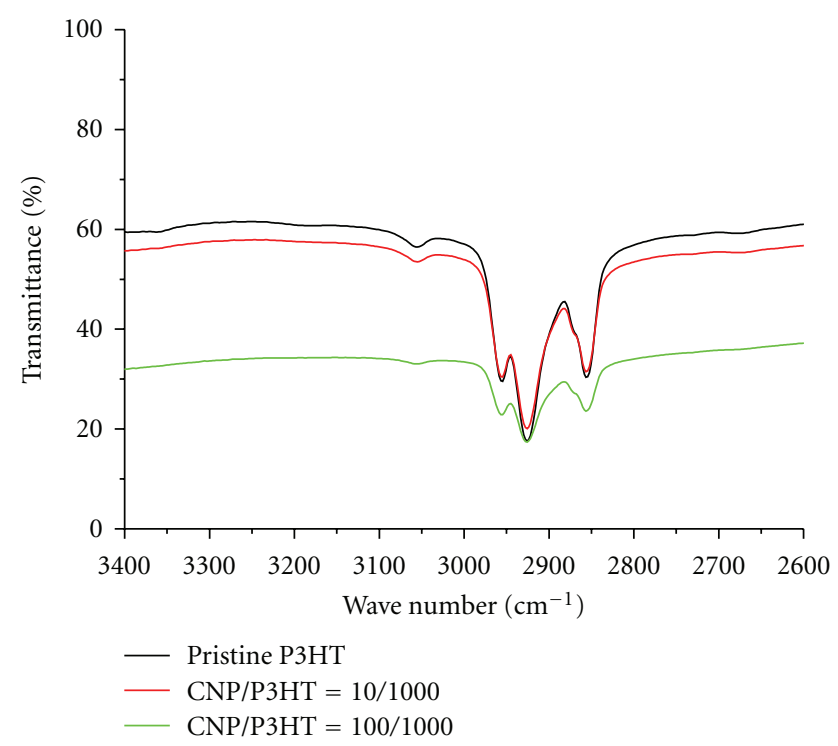

FIgURe 6: FTIR image of pristine CNP/P3HT and different CNP concentrations.

enhancement can be demonstrated as the transconductance improvement shown as Table 2. It should be noted that this tranconductance is extracted from $\mathrm{I}_{D}^{1 / 2}-\mathrm{V}_{\mathrm{GS}}$ curve. The transconductance can be determined at $\mathrm{V}_{\mathrm{DS}}=-20 \mathrm{~V}$ by using the linear region drain current equation.

\section{Conclusions}

In summary, we have examined a CNP/P3HT blending semiconductor material for inkjet-printed OFETs. As $\mathrm{CNP} / \mathrm{P} 3 \mathrm{HT}$ concentration increases, the effective carrier mobility of each fabricated OFET increases. This carrier mobility enhancement is 8 folds for the comparison between pristine $\mathrm{P} 3 \mathrm{HT}$ without $\mathrm{O}_{2}$ plasma treatment and $\mathrm{CNP} / \mathrm{P} 3 \mathrm{HT}$ $=10 \mathrm{wt} . \%$. At the same time, the on-off ratio of fabricated OFETs is kept above $10^{4}$. Based on the observation of SEM, $\mathrm{XRD}$, and FTIR, this improvement can be contributed to the local field enhancement and the hole-injection lowering by CNP/P3HT complexes. This work offers a low-cost and effective semiconductor material for inkjet-printing technology in the development of organic electronics.

\section{Acknowledgments}

the authors would like to thank Dr. Yi-Jun Lin of Taiwan Textile Research Institute for her suggestion in material experiments. This work is supported by National Science Foundation (Grant no. NCS 98-2218-E-002-042, NSC 982221-E-002-139-MY, NSC 98-2627-E-002-003, and NSC992911-I-002-001).

\section{References}

[1] T. Shimoda, Y. Matsuki, M. Furusawa et al., "Solutionprocessed silicon films and transistors," Nature, vol. 440, no. 7085, pp. 783-786, 2006.

[2] G. H. Gelinck, H. E. A. Huitema, E. V. Veenendaal et al., "Flexible active-matrix displays and shift registers based on solution-processed organic transistors," Nature Materials, vol. 3, no. 2, pp. 106-110, 2004.

[3] S. H. Eom, S. Senthilarasu, P. Uthirakumar et al., "Polymer solar cells based on inkjet-printed PEDOT:PSS layer," Organic Electronics, vol. 10, no. 3, pp. 536-542, 2009.

[4] C. N. Hoth, P. Schilinsky, S. A. Choulis, and C. J. Brabec, "Printing highly efficient organic solar cells," Nano Letters, vol. 8, no. 9, pp. 2806-2813, 2008.

[5] Y. K. Kim, K. Lee, N. E. Coates et al., "Efficient tandem polymer solar cells fabricated by all-solution processing," Science, vol. 317, no. 5835, pp. 222-225, 2007.

[6] C. D. Müller, A. Falcou, N. Reckefuss et al., "Multicolour organic light-emitting displays by solution processing," Nature, vol. 421, no. 6925, pp. 829-833, 2003.

[7] S. I. Park, Y. J. Xiong, R. H. Kim et al., "Printed assemblies of inorganic light-emitting diodes for deformable and semitransparent displays," Science, vol. 325, no. 5943, pp. 977-981, 2009.

[8] P. F. Baude, D. A. Ender, M. A. Haase, T. W. Kelley, D. V. Muyres, and S. D. Theiss, "Pentacene-based radio-frequency identification circuitry," Applied Physics Letters, vol. 82, no. 22, pp. 3964-3966, 2003. 
[9] B. Crone, A. Dodabalapur, A. Gelperin et al., "Electronic sensing of vapors with organic transistors," Applied Physics Letters, vol. 78, no. 15, pp. 2229-2231, 2001.

[10] J. A. Lim, J. H. Kim, L. Qiu et al., "Inkjet-printed singledroplet organic transistors based on semiconductor nanowires embedded in insulating polymers," Advanced Functional Materials, vol. 20, no. 19, pp. 3292-3297, 2010.

[11] C. W. Sele, T. von Werne, R. H. Friend, and H. Sirringhaus, "Lithography-free, self-aligned inkjet printing with subhundred-nanometer resolution," Advanced Materials, vol. 17, no. 8, pp. 997-1001, 2005.

[12] Y. Y. Noh, N. Zhao, M. Caironi, and H. Sirringhaus, "Downscaling of self-aligned, all-printed polymer thin-film transistors," Nature Nanotechnology, vol. 2, no. 12, pp. 784 789, 2007.

[13] J. Y. Z. Zhang, Z. Wei, Y. Sum et al., "Inkjet-printed organic electrodes for bottom-contact organic field-effect transistors," Advanced Functional Materials, vol. 21, no. 4, pp. 786-791, 2011.

[14] E. Tekin, P. J. Smith, S. Hoeppener et al., "InkJet printing of luminescent CdTe nanocrystal-polymer composites," Advanced Functional Materials, vol. 17, no. 1, pp. 23-28, 2007.

[15] Y. D. Park, H. S. Lee, Y. J. Choi et al., "Solubility-induced ordered polythiophene precursors for high-performance organic thin-film transistors," Advanced Functional Materials, vol. 19, no. 8, pp. 1200-1206, 2009.

[16] S. Gamerith, A. Klug, H. Scheiber, U. Scherf, E. Moderegger, and E. J. W. List, "Direct ink-jet printing of Ag-Cu nanoparticle and Ag-precursor based electrodes for OFET applications," Advanced Functional Materials, vol. 17, no. 16, pp. 3111-3118, 2007.

[17] H. Sirringhaus, P. J. Brown, R. H. Friend et al., "Twodimensional charge transport in self-organized, high-mobility conjugated polymers," Nature, vol. 401, no. 6754, pp. 685-688, 1999.

[18] F. M. Li, A. Nathan, Y. L. Wu, and B. S. Ong, "A comparative study of plasma-enhanced chemical vapor gate dielectrics for solution-processed polymer thin-film transistor circuit integration," Journal of Applied Physics, vol. 104, no. 12, Article ID 124504, 2008.

[19] G. C. Yuan, Z. S. Lu, Z. Xu et al., "Microstructure transformations induced by modified-layers on pentacene polymorphic films and their effect on performance of organic thin-film transistor," Organic Electronics, vol. 10, no. 7, pp. 1388-1395, 2009.

[20] L. Jiang, J. Zhang, D. Gamota, and C. G. Takoudis, "Enhancement of the field-effect mobility of solution processed organic thin film transistors by surface modification of the dielectric," Organic Electronics, vol. 11, no. 2, pp. 344-350, 2010.

[21] J. Tsukamoto, J. Mata, and T. Matsuno, "Organic field effect transistors using composites of semiconductive polymers and single-walled carbon nanotubes," Japanese Journal of Applied Physics, vol. 46, no. 17-19, pp. L396-L398, 2007.

[22] S. H. Liu, S. C. B. Mannsfeld, M. C. Lemieux, H. W. Lee, and Z. N. Bao, "Organic semiconductor-carbon nanotube bundle bilayer field effect transistors with enhanced mobilities and high on/off ratios," Applied Physics Letters, vol. 92, no. 5, Article ID 053306, 2008.

[23] Y. D. Park, J. A. Lim, J. A. Yunseok et al., "Enhancement of the field-effect mobility of poly(3-hexylthiophene)/functionalized carbon nanotube hybrid transistors," Organic Electronics, vol. 9, no. 3, pp. 317-322, 2008.

[24] Y. J. Song, J. U. Lee, and W. H. Jo, "Multi-walled carbon nanotubes covalently attached with poly(3-hexylthiophene) for enhancement of field-effect mobility of poly(3-hexylthiophene)/multi-walled carbon nanotube composites," Carbon, vol. 48, no. 2, pp. 389-395, 2010.

[25] M. W. Lee and C. K. Song, "Oxygen plasma effects on performance of pentacene thin film transistor," Japanese Journal of Applied Physics, vol. 42, no. 7 A, pp. 4218-4221, 2003.

[26] B. J. Song, K. Hong, W. K. Kim, K. Kim, S. Kim, and J. L. Lee, "Effect of oxygen plasma treatment on crystal growth mode at pentacene/Ni interface in organic thin-film transistors," Journal of Physical Chemistry B, vol. 114, no. 46, pp. 1485414859, 2010.

[27] M. Bruening, E. Moons, D. Cahen, and A. Shanzer, "Controlling the work function of CdSe by chemisorption of benzoic acid derivatives and chemical etching," Journal of Physical Chemistry, vol. 99, no. 20, pp. 8368-8373, 1995.

[28] A. Paskaleva and E. Atanassova, "Bulk oxide charge and slow states in $\mathrm{Si}-\mathrm{SiO} 2$ structures generated by RIE-mode plasma," Microelectronics Reliability, vol. 40, no. 12, pp. 2033-2037, 1999.

[29] Y. D. Park, J. A. Lim, J. A. Yunseok et al., "Enhancement of the field-effect mobility of poly(3-hexylthiophene)/functionalized carbon nanotube hybrid transistors," Organic Electronics, vol. 9, no. 3, pp. 317-322, 2008. 

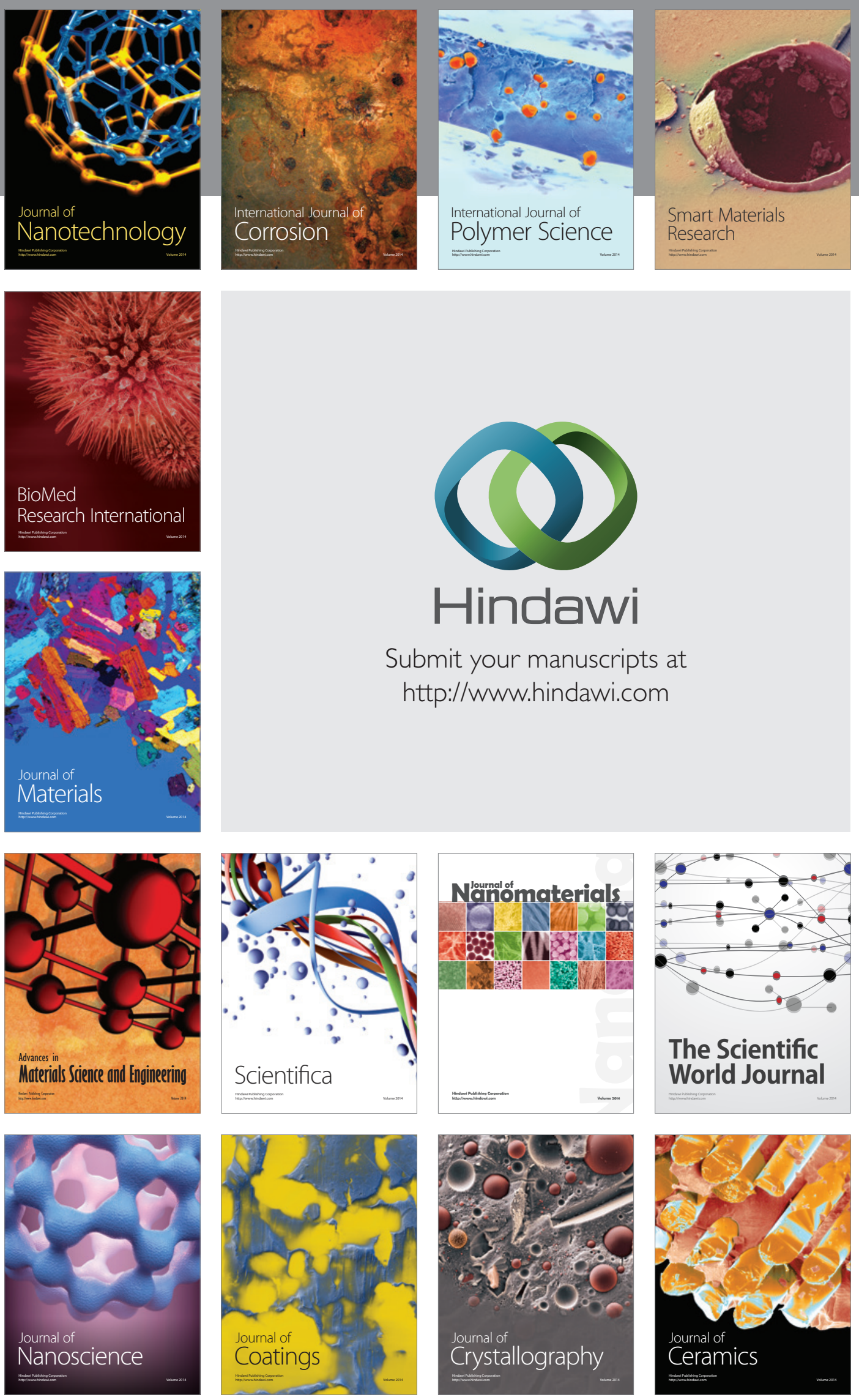

The Scientific World Journal

Submit your manuscripts at

http://www.hindawi.com

\section{World Journal}

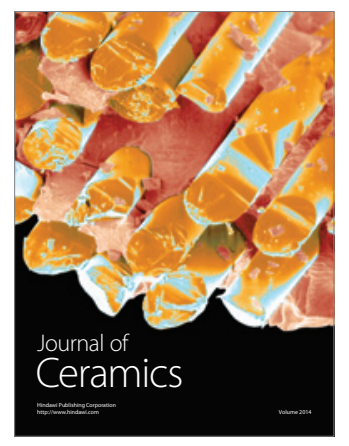

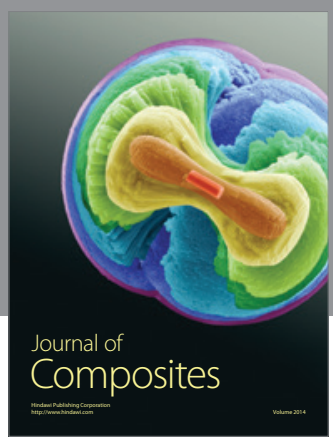
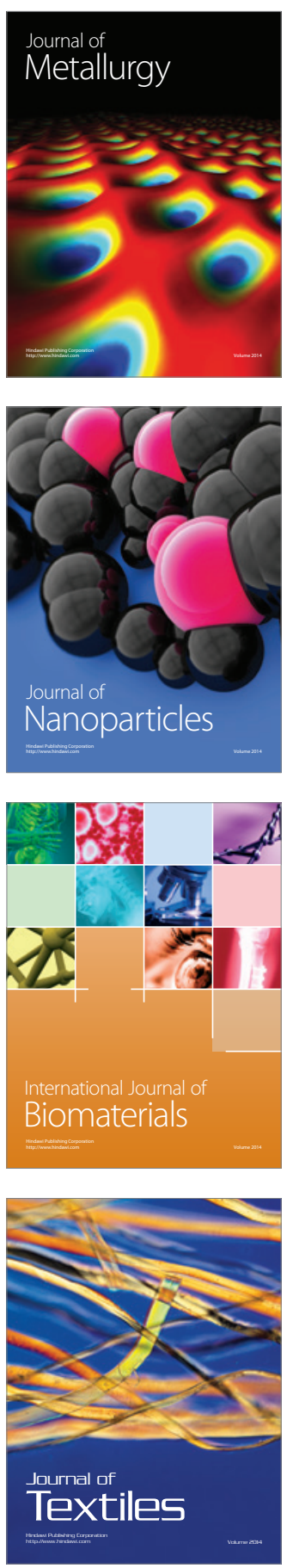